\title{
Tradition and the Individual Talent - T. S. ELIOT- A Critical Elucidation
}

\author{
G Ratna papa \\ Lecturer in English \\ VRS\& YRN College Chirala, Prakasam D.T. A.P. India
}

\begin{abstract}
In English writing we seldom speak of tradition, though we occasionally apply its name in deploring its absence. We cannot refer to 'the tradition' or to 'a tradition'; at most, we employ the adjective in saying that poetry of So-and-so is 'traditional' or even 'too traditional'. Seldom, perhaps, does the word appears except in a phrase of censure. If otherwise. it, it is vaguely a probative, with the implication, as to the work approved, of some pleasing archeological reconstruction. You can hardly make the word agreeable to English ears without this comfortable reference to the reassuring science of archaeological science of archeology.

However, for my article presentation I chosen the title "Tradition and the Individual Talent-T.S.Eliot- A critical Elucidation" through which I tried to convey the meaning my paper's content which certainly the word is not likely to appear in our appreciations of living or dead writers. Every nation, every race, has not only its own critical turn of mind; and is even more oblivious of the shortcomings and limitations of its critical habits than of those of its creative genius. We know, or think we know, from the enormous mass of critical writing that has appeared in the French language the critical method or habit of the French; we only conclude (we are such unconscious people) that the French are critical, and sometimes even plume ourselves a little with the fact, as if the French were the less spontaneous. Perhaps they are; but we might remind ourselves that criticism is as inevitable as breathing and that we should be none the worse for articulating what passes in our minds when we read a book and feel an emotion about it, for criticizing our own minds in their work of criticism.
\end{abstract}

Keywords: Tradition, criticism, emotions, resembles, elucidation.

\section{INTRODUCTION}

One of the facts that might come to light in this process is our tendency to insist, when we praise a poet, upon those aspects of his work in which he least resembles anyone else, In these aspects of his work we pretend to find what is individual, what is the peculiar essence of the man. We dwell with satisfaction upon the poet's difference from his predecessors, especially his immediate predecessors; his immediate predecessors; we endeavor to find something that can be isolated in order to be enjoyed. whereas if we approach a poetry without this prejudice we shall often find that only the best, but the most individual part of his work may be those in which the dead poets, his ancestor, assert their immortality most vigorously. And I do not mean the impression period of adolescence, but the period of full maturity.

Yet if the only form of tradition, of handling down, consisted in following the ways of the immediate generation before us in a blind or timid adherence to its success, 'tradition' should positively be discouraged. We have seen many such simple currents soon lost in the sand; and novelty is better than repetition. Tradition is a matter of much wider significance. It cannot be inherited, and if you want it you must obtain it by great labor, it involves, in the first place, the historical sense, which we may call indispensable to anyone who would continue to be a poet beyond his twenty-fifth year; and the historical sense compels a man to write not merely with his own generation in his bones, but with a feeling with a whole of the literature of Europe from Homer and within it the whole of the literature of his own country has a simultaneous existence and composes a simultaneous order. This historical sense, which is a sense of the timeless as well as of the temporal and of the timeless and of the temporal together, is what makes a writer traditional. Ad it is at the same time what makes a writer most acutely conscious of his place in time, of his own contemporaneity. 


\section{G Ratna Papa}

No poet, no artist of any art, has his complete meaning alone. His significance, his appreciation is the appreciation of his relation to these dead poets and artists. You cannot value him alone; you must set him, for contrast and comparison, among the dead. I mean this is a principle of aesthetic, not merely historic criticism. The necessity that we shall confirm, that he shall cohere, is not one-sided; what happens when a new work of art is created is something that happens simultaneously to all the works of art which preceded it. The existing monuments form an ideal order among themselves, which is modified by the introduction of the new ( the really new) work of art among them. The existing order is complete before the New York arrives; for order to persist after the supervision of novelty, the whole existing order must be, if so slightly, altered ; and so the relations, proportions, values of each work of art toward the whole are readjusted; and this is the conformity between the old and the new. Whoever has approved this idea of order, of the form of European, of English literature will not find it preposterous that the past should be altered by the present as much as the present is directed by the past. And the poet who is aware of this will be aware of great difficulties and responsibilities.

In a peculiar sense he will be aware also that he must inevitably be judged by the standards of the past. I say judged, not amputated, by them; not judged to be as good as, or worse or better than , the dead; and certainly not judged by the canons of dead critics. It is a judgment, a comparison, in which two things are measured by each other. To confirm merely would be for the new work not really to confirm at all; it would not be new, and would therefore would not be a work of art. And we do not quite say that new is more valuable because it fits in; but it's fitting in is a test of its value - a test, it's true, which can be slowly and cautiously applied, for we are none of us infallible judges of community. We say: it appears to conform, and is perhaps individual, or it appears individually, and may conform; but we are hardly likely to find that this is one and not the other.

\section{Critical Elucidation - Tradition AND the Individual Talent}

To proceed to a more intelligible exposition of the relation of the poet to the past: he can neither take the past as lump, and indiscriminate bolus, nor can he form himself wholly no one or two private admirations, nor he can form himself upon one preferred period. The first course is inadmissible, the second is an important experience of the youth, and the third is a pleasant and highly desirable supplement. The poet must be very conscious of the main current, which does not at all flow in variably through the most distinguished reputations. He must be quite aware of the obvious fact that art never improves, but that the material art is never quite the same. He must be aware that the mind of Europe - the mind of his own country - a mind which he learns in time to be much more important than his own private mind - is a mind which changes, and that this change is a development which abandons nothing en route, which does not superannuate either Shakespeare, or Homer, or the rock drawing of the Magdalenian draughtes men. That this development, refinement perhaps, complication certainly, is not, from the point of view of the artist, any improvement. Perhaps not even an improvement from the point of view of the psychologist or not to the extent which we imagine; perhaps only in the end based upon a complication in Economics and machinery. But the difference between the present and the past is that the conscious present is an awareness of the past in a way and to an extent which the past's awareness of itself cannot show.

Someone said: ' the dead writers are remote from us we know so much more than they did'. Precisely, and they are that which we know.

I am alive to a usual objection to what is clearly part of my program me for the métier of poetry. The objection is that the doctrine requires a ridiculous amount of erudition (pedantry), a claim which can be rejected by appeal to the lives of poets in any pantheon. It will even be affirmed that much learning deadens perverts poetic sensibility. While, however, we, persist in believing that a poet ought to know as much as will not encroach upon his necessary receptivity and laziness, it is not desirable to confine knowledge to confine to whatever can be put into a useful shape for examinations, drawing rooms, or the still more pretentious modes of publicity. Some can absorb knowledge, the more tragedy must sweat for it. Shakespeare acquired more essential history from Plutarch than most men could from the whole British museum. What is to be insisted upon is that the poet must develop or procure the consciousness throughout his carrier.

What happens is a continual surrender of himself as he is at the moment to something which is more valuable. The progress of an artist is a continual self-sacrifice, a continual extinction personality.

There remains to define this process of depersonalization and its relation to the sense of tradition. It is 
in this depersonalization that art may be said to approach the condition of science. I therefore invite you to consider, as a suggestive analogy, the action which takes place when a bit of finely affiliated platinum is introduced into a chamber containing oxygen and sulphurdioxide.

Honest criticism and sensitive appreciation is directed not upon the poet but upon the poetry. If we attend to the confused cries of the newspaper critics and the susurrus of popular repetition that follows, we shall hear the names of poets in great numbers; if we seek not Blue-book but the enjoyment of poetry, and ask for a poem, we shall seldom find it. I have tried to point out the importance of the relation of the poem to other poems by other authors, and suggest the conception of poetry as a living whole of all the poetry that has ever been written. The other aspect of this impersonal theory of poetry is the relation of the poem to its author. And I hinted, by an analogy, that the mind of mature poet differs from that of the immature one not precisely in any valuation of 'personality', not being necessarily more int6eresting, or having ' more to say', but rather by being a more finely perfected medium in which special, or very varied, feelings are at liberty to enter into new combinations.

The analogy was that of the catalyst. When the two gases previously mentioned are mixed in the presence of a filament of platinum, they form sulphurs acid. This combination takes place only if the platinum is present; nevertheless the newly formed acid contains no trace of platinum, and the platinum itself is apparently unaffected: has remained inert, neutral, and unchanged. The mind of the poet is the shred of platinum. It may partly or exclusively operate upon the experience of the man himself; but, the more perfect the artist, the more completely separate in him will be the man who snuffers and the mind which creates; the more perfectly will the mind digest and transmute the passions which are its material.

The experience, you will notice, the elements which enter the presence of the transforming catalyst, are of two kinds: emotions and feelings. The effect of a work of art upon the person who enjoys it is an experience not of art. It may be formed out of one emotion, or may be a combination of several; and various feelings; inhering for the writer in particular words or phrases or images, may be added d to compose the final result. Or great poetry may be made without the direct use of any emotion whatever: composed out of feelings solely. Canto XV of the inferno (Brunetto Latini) is a working up of the emotion evident in the situation; but the effect, though single as that of any work of art, is obtained by considerable complexity of detail. The last quatrain gives an image, a feeling, attaching to an image, which 'came' which did not develop simply out of what precedes, but which was probably in suspension in the poet's mind until the proper combination arrived for it to add itself to. The poet's mind is in fact a receptable for seizing the storing up numberless feelings, phrases, images, which remain there until all the particles which can unite to form a new compound are present together.

If you compare several representative passages of the greatest poetry you see how great is the variety of types of combination, and also how completely any semi-ethical criterion of; 'sublimity' misses the mark. For it is not the 'greatness', the intensity of the artistic process, the pressure, so to speak, under which the fusion takes place, that counts. The episode of Paolo and Francesca employs a definite emotion, but the intention of the poetry is something quite different from whatever intensity in the supposed experience it may give the impression of. It is more intense, furthermore, than canto XXVI, the voyage of Ulysses, which has not the direct dependence upon an emotion. Great variety is possible in the process of transmutation of emotion: the murder of Agamemnon, or the agony of Othello, gives an artistic effect apparently closer to a possible original than the scenes from Dante. In the Agememenon, the artistic emotion approximates to the emotion of an actual spectator; in Othello to the emotion of the protagonist himself. But the difference between art and event is always absolute; the combination which is the murder of Agamemnon is probably as complex as that which is the voyage of Ulysses. In either case there has been a fusion of elements. The ode of Keats contains a number of feelings which have nothing particular to do with the nightingale, but which the nightingale, partly perhaps because of its attractive name, and partly because of its reputation, served to bring together.

The point of view which $\mathrm{i}$ am struggling to attack is perhaps to the metaphysical theory of the substantial unity of the soul: for my meaning is, that the poet has, not a 'personality' to express, but a particular medium, which is only a medium and not a personality, in which impressions and experiences combine in peculiar and unexpected ways. Impressions and experiences which are important for the man may take no place in the poetry, and those which become important in the 
poetry may play quite a negligible part in the man, the personality.

I will quote a passage which is unfamiliar enough to be regarded with fresh attention in the light- or darkness - of these observations:

And now methinks I could even chide myself

For donating on her beauty, though her death

Shall be revenged after no common action

Does the silkworm expend her yellow labours

For thee? For thee does she undo herself?

Are lordships sold to maintain lady ships

For the poor benefit of a bewildering minute?

Why does yon fellow falsify highways?

And put his life between the judge's lips,

To refine such a thing - keep horse and men

To beat their velours for her?

In this passage (as is evident if it is taken in its context) there is a combination of positive and negative emotions: an intensively strong towards beauty and an equally intense fascination by the ugliness which is contrasted with it and which destroys it. This balance of contrasted emotion is in the dramatic situation to which the speech is pertinent, but that situation alone is inadequate to it. This is, so to speak, the structural emotion, provided by the drama. But the whole effect, the dominant tone, is due to the fact that number of floating feelings, having an affinity to this emotion by no means superficially evident, have combined with to give us a new art emotion.

It is not in his personal emotions, the emotions provoked by particular events in his life that the poet is in any way remarkable, or interesting. His particular emotions may be simple, or crude or flat. The emotion in his poetry will be a very complex thing, but not with the complexity of the emotions of the people who have very complex or unusual emotions in life. One error, in fact, of eccentricity in poetry to seek for new human emotions to express; and in this search for novelty in the wrong place it discovers the preserve. The business of the poet is not to find new emotions, but to use the ordinary ones and, in working them up into poetry, to express feelings which are not in actual emotions at all. And emotions which he has never experienced will serve his turn as well as those familiar to him. Consequently we must believe that ' emotion recollected in tranquility' is an inexact formula. For it is neither emotion, nor collection, nor, without distortion of meaning, tranquility. It is a concentration, and a new thing resulting from the concentration, of a very great number of experiences which to the practical and the active person would not seem to be experiences at all; it is a concentration which does not happen consciously or of deliberation. These experiences are not' recollected', and they finally unite in an atmosphere which is 'tranquil' only in that it is a passive attending upon the event. Of course this is not quite the whole story. There is a Great deal, in the writing of poetry, which must be conscious and deliberate. In fact the bad poet is usually unconscious where he ought to be conscious, and conscious where he ought to be unconscious. Both errors tend to make him 'personal'. Poetry is not a turning loose of emotion; but an escape from emotion; it is not expression of personality, but an escape from personality. But, of course, only those who have personality and emotions know what it means to want to escape from these things.

\section{Conclusion}

This article proposes to halt at the frontier of metaphysics or mysticism, and confine itself to such practical conclusions as can be applied by the responsible person interested in poetry. To divert interest from the poet to the poetry is a laudable aim: for it would conduce to a jester estimation of actual poetry, good and bad. There are many people who appreciate the expression of sincere emotion in verse, and there is a smaller number of people who can appreciate technical excellence. But very few know when there is an expression of significant emotion, emotion which has its life in the poem 
and not in the history of the poet. The emotion of art is impersonal. And the poet cannot reach this impersonality without surrendering himself wholly to the work to be done. And he is not likely to know what is to be done unless he lives in what is not merely the present, but the present moment of the past, unless he is conscious, not of what is dead, but of what is already living.

\section{REFERENCES}

Coleridge T.S. A critical companion of Waste Land of 1988 Print.

Eliot T.S. The waste Land, A Critical companion on T.S Eliot P 221- 2501989 Print

Enright D.J English Critical Texts, 1988. Print.

Keats John, Critical Poems on criticism and literature Page 155-160. 1967 Print. 